\title{
LVII. On the purification of nickel, with some remarks on the solutions of metallic oxides in ammonia, \&c.
}

\author{
Mr. R. Phillips
}

To cite this article: Mr. R. Phillips (1803) LVII. On the purification of nickel, with some remarks on the solutions of metallic oxides in ammonia, \&c. , Philosophical Magazine Series 1, 16:64, 312-317, DOI: $10.1080 / 14786440308676351$

To link to this article: http://dx.doi.org/10.1080/14786440308676351

曲 Published online: 18 May 2009.

Submit your article to this journal $\pi$

Џll Article views: 2

Q View related articles $\sqsubset$ 
lacious indications of strength without its being perceived by the owner of them. The fact is, however, that although, for certain purposes, where metallic instruments cannot be used on account of their being liable to corrosion (as in the case of the mineral acids) we are obliged to employ glass, yet they are by no means capable of being rendered so accurate as those which are made of metal. The proportion of the bulb to the stem, and the consequent extent of the graduations, are, of course, within certain limits, matters of mere chance; and they are, therefore, not the subject of calculation. Every such instrument can only be graduated by direct experiment: and to those who would contend for the eligibility of such a method, where the other can be used, we can only say, that they have not sufficiently considered the subject. The metallic stems and bulbs, on the other hand, are by the tools employed for these purposes capable of being reduced so accurately to the required bulk, that the error in any point of the scale on this account will not amount to one-tenth of an unit in the specific gravity. Nor is it true that it is easily possible for the effect of such an accident to pass unnoticed by any one who ought to be entrusted with the use of an instrument at all. The least want of proper convexity in the bulb strikes the eye in an instant, even before its effect would be such as to be perceptible in the indication on the stem; and if it were not so, the simple operation of immerging the hydrometer, loaded with its proper weight in distilled or rain water at $60^{\circ}$, would at once detect such a circumstance, so that no probable inconvenience can ever result from such a cause.

[ To be continued.]

LVII. On the Purification of Nickel, with some Remarks on the Solutions of metallic Oxides in Ammonia, EOc. By Mr. R. Phillips, Momber of the Askesian and British Mineralogical Societies*.


tury, yet it existence as a peculiar metal has not been so well established but that several chemists, even of late years, have entertained considerable doubt on the subject. This has probably been occasioned by the difficulty in separating it from the metals with which it is usually mixed. Of these copper and cobalt, and more particularly the latter, strongly

* Communicated by the Author.

resemble 
resemble it in some of its chemical habitudes. On account of its magnetic property, it has been supposed impossible to divest it of iron; and until the method lately adopted by R. Chenevix, esq. no certain means appear to have been known for the separation of the arsenic.

In order to purify this metal the following method may be adopted, which includes that above alluded to for the separation of the arsenic. I,et nickel be dissolved in dilute nitric acid to complete saturation; to the filtered solution add mitrate of lead in sufficient quantity to precipitate the arsenic acid. If more should be employed than is required, the excess occasions no inconvenience. Having separated the arseniate of lead by the filter, add a small quantity of nitric acid to the solution, and immerse a bar of iron to precipitate the copper. This being done, there remain in solution the oxides of nickel, cobalt, iron, and lead, which may be precipitated by carbonate of potash. The precipitate, after sufficient washing, is to be put, while moist, into a solution of ammonia, which, dissolving the oxides of nickel and cobalt, leaves those of iron and lead to be separated by filtration.

All that is now necessary is to separate the oxides of cobalt and nickel, in order to complete the purification of the latter : but beforc the experiments for this purpose are related, it may not be amiss to state the properties of the ammoniacal solutions of some of the metallic oxides, although the habitudes of all of them are not immediately connected with the present inquiry. These I prepared by precipitating the oxides from their solutions in acid, and putting them, while moist, into solution of ammonia. Notwithstanding this is the most favourable state for the ammonia to act upon them, yet in every case, even after long digestion, the ammonia is in excess, since a part of it may be evaporated without causing any precipitation of the oxide. As these solutions possess different properties when the ammonia is in excess and when it is not, in the following experiments I shall call the former solution, and the latter evaporated solution. The evaporation was continued until moist turmeric paper, when held over the solutions, suffered no change.

Solution of oxide of silver in ammonia. Colourless : is not decomposed by water. Evaporated solution-Speedily decomposed by water: the precipitate blueish white, becoming gradually brown by exposure to light.

Solition of oxide of copper in ammonia.-Colour purple. 
It is not decomposed by water.-The evaporated solution is immediately decomposed by it.

Solution of oxide of colalt in ammonia.-Colour deep red: not decomposed by water. Nor is the evaporated solution decomposed by water, even when so diluted as to be nearly colourless.

Solution of oxide of nickel in ammonia. - Colour greenish blue : slowly decomposed by water. Evaporated solutionColour pure green : decomposed immediately by water.

As silver and copper may be easily obtained from their solutions by well-known methods, the above-related experiments are more particularly applicable for the separation of cobalt and nickel; especially as the properties of their solutions differ very materially. But as the precipitation by water is often incomplete, and always inconvenient on account of the quantity necessarily employed, without examining the extent of its effects in the present instance, I tried other methods to effect the separation of these oxides, and, after some fruitless attempts, found potash answer this purpose extremely well. When a solution of it is added to the ammoniacal solutions of metallic oxides, the effects pro. duced are as follow:

Solution of oxide of silver in ammonia.-Slowly decomposed, requiring three or four days for its completion. The precipitate is blackish brown. I have not examined whether it is fulminating. Evaporated solution-Immediately decomposed : the precipitate is of a lighter brown than the former.

Solution of oxide of copper in ammonia.-Slowly decom. posed, and in very small quantity. Evaporated solutionQuickly decomposed.

Solution of oxide of cobalt in ammonia.-Very slowly and sparingly decomposed, even by large quantities of the solution of potash, and more slowly as the solution is more dilute. Evaporated solution, by the addition of potash, gradually changes from red to pink ; then becomes scarlet, at. length turns brown, and deposits brown oxide of cobalt. If a quantity of solution of potash be added to a small quantity of the evaporated solution, precipitation ensues in a ferw hours; but if a considerable quantity of water be added to similar quantities of the evaporated solution, and of potash, five or six days are required to complete the precipitation.

Solution of oxide of nickel in ammonia.-Immediately decomposed, and the more readily as it is more diluted. Evar porated solution-The same properties in a greater degree. 
By comparing the above statements it appears proper, for the separation of the oxides in question, that the solution containing them should have the ammonia in excess, and be largely diluted before the addition of the potash. The excess of ammonia prevents, for a considerable length of time, any precipitation of the oxide of cobalt, while it produces no delay in the precipitation of the oxide of nickel. Mere dilution precipitates a part of the oxide of nickel; and at the same time that it renders the remainder more easy of precipitation, it prevents for several days any deposition of the oxide of cobalt. The following experiment will show that this method may be relied upon:

To a measure of solution of oxide of nickel in ammonia $I$ added solution of potash as long as precipitation took place. The precipitate was washed, dried, and weighed. As it appeared probable that all the oxide of nickel might not be precipitated, I heated the solution after filtration till the ammonia had evaporated, but I did not obtain any further quantity of oxide.

To a similar measure of the same solution of oxide of nickel I added a measure of solution of oxide of cobalt in ammonia, and precipitated by potash. The precipitate appeared to be pure oxide of nickel; and, after drying, its weight did not differ 1-10th of a grain from that of the oxide of nickel obtained in the former experiment. This experiment was repeated with nearly similar results.

Soda produces the same effects as potash, and appears to act rather more readily ; but whether in smaller quantity than the latter I have not tried. Carbonate of potash produces no effect. The decomposition of the ammoniacal solutions by potash appears to depend upon a combination of the two alkalies; the compound possessing, as is usual in chemical combinations, properties either partially or totally differing from those of its constituents. That this precipitation does not depend upon dilution has, I think, been already shown; and the following experiments more clearly determine that it must be ascribed to some other cause:

To one measure of solution of ammonia I added three measures of water. Moist oxide of nickel put into this dilute solution quickly coloured it. After several days digestion the solution decomposed by potash furnished nearly four grains of oxide.

One measure of solution of ammonia was mixed with three measures of dilute solution of potash. After as long digestion with moist oxide of nickel as in the former case, the 
solution had not acquired any colour; and on evaporating the ammonia no oxide of nickel was obtained.

As far as I have examined, the solutions of oxides in ca:bonate of ammonia possess the same properties as those in ammonia ; for although carbonate of potash does not decompose the latter, yet the former are decomposed by potash. This is easily explained. Potash has a stronger affinity for carbonic acid than ammonia has : when, therefore, a carbonated ammoniacal solution is decomposed by it, a part of the potash combines with the carbonic acid of the carbonate of ammonia, and the remaining part decomposes what by the action of the other has become ammoniacal solution.

Considering that the supposition of a combination of the two alkalies would be strengthened if the experiments which gave rise to it could be reversed, i. e. if it were possible to precipitate with ammonia substances dissolved by potash, I dissolved in the latter silica, alumina, and several metallic oxides. On adding ammonia to these solutions, I at first thought I had succeeded in obtaining precipitates; but upon examining the ammonia employed, I found that it contained a small quantity of carbonic acid ; and that when ammonia free from it was used, no precipitate was in any case obtained. Although these experiments did not succeed in supporting the above supposition, yet they are by no means fatal. to it. It is probable that potash has a stronger affinity for the substances which it dissolves than it has for ammonia; and in this case, as no combination could be effected, no precipitation would ensue. In the first experiments potash and ammonia seem to possess a stronger affinity for each other than ammunia has for the oxides soluble in it.

Judging by the effects produced by water and potash, the affinity of ammonia for the metallic oxides appears to be as follows:

$$
\begin{aligned}
& \text { Oxide of cobalt, } \\
& \text { Oxide of copper, } \\
& \text { Oxide of silver, } \\
& \text { Oxide of nickel. }
\end{aligned}
$$

I reduced a quantity of the oxide of nickel, obtained by the above-described process, and obtained a button of metal which exhibited the followir $\mathrm{g}$ properties :

Colour-Dull yellowish white.

Fracture-Foliated. Specific gravity 8.51.

Fragile, but capable of slight extension by hammering. Strongly magnetic. 
In one of the late French journals it is proposed to separate the oxides of cobalt and nickel by oxidizing the former by means of the hyperoxygenized muriatic acid. I have tried the method recommended without success.

\section{On Machines for measuring Elasticity. By a Friend to Physical Inquiries.}

\section{To the Editor of the Philosophical Magazine.} SIR,

A

FEw years ago an eminent botanist, now abroad, being desirous of ascertaining the comparative elasticity of different woods, was wishing to have some machine made for that purpose; but whether or not any such machine has been yet made I am not acquainted. At the same time the subject was mentioned the following contrivances occurred to my mind, which, if carried into execution, might in some measure answer the purpose ; and if you think them worth communicating to the public, I shall be glad to see them noticed in your magazine. They mav serve for some of your readers as hints to improve on, and be the means of some much more accurate method of ascertaining the elasticity of bodies being invented.

First Contrivance.-A machine might be made which should have a flap on which balls of different sorts of wood, or other substances, might be placed, and suddenly let fall on a slab of ivory or marble: on this machine there should be an upright graduated post in order to see to what height each ball rebounded; by which, in some instances, the comparative elasticity of the body subjected to trial might be judged of.

Olservations.-This method, in order to be accurate, should be tried in the exhausted receiver of an air-pump; otherwise with light bodies, such as cork and elder-pith, both very elastic, the experiment will not answer. The instrument for performing the common gainea-and-feather operation might, perhaps, be as good a contrivance as any : a wire cage might be placed under the recciver in order to protect the glass. Bodies of nearly the same gravity might be tried in the air. The standard ball might be ivory let fall on ivory, or marble let fall on marble.

Second Contrivance.- Thin slips of different sorts of wood, \&c. might be bent half round a circular piece of board, 